\title{
RECONSTRUCCIÓN PERINEAL INMEDIATA EN EXTENSA RESECCIÓN ABDOMINOPERINEAL RECTAL*
}

\author{
Drs. Ricardo Yáñez M. ${ }^{1}$, Esteban Torres E. ${ }^{1}$, Cristóbal Maíz H. ${ }^{1}$, \\ Ignacio Cifuentes O. ${ }^{1}$, Fernanda Deichler V. ${ }^{2}$, Marcel Sanhueza G. ${ }^{1}$, \\ Julio Reyes R. ${ }^{1,2}$, Rodrigo Kusanovich B. ${ }^{1,2}$, Francisca León G. ${ }^{1}$ \\ 1 Servicio de Cirugía, Hospital Dr. Sótero del Río. \\ 2 Escuela de Medicina, Pontificia Universidad Católica de Chile. \\ Santiago, Chile.
}

\begin{abstract}
Immediate perineal reconstruction after vast rectal abdominoperineal resection

Background: Buschke-Lowenstein tumor is a benign skin lesion secondary to human papilloma virus infection. It usually appears as an exophytic anogenital mass and may progress to a squamous cell carcinoma. It can be treated with chemo, radio or immunotherapy and occasionally it requires radical surgery. Case report: We report a 53 years old male with a perianal lesion lasting 15 years that was treated with chemoradiotherapy that relapsed with malignant transformation. Since the pathological study showed a squamous cell carcinoma, a rectal abdominoperineal resection was planned. The defect that left the surgical procedure was covered with musculocutaneous flaps from gracilis muscle of the thigh.
\end{abstract}

Key words: Squamous cell carcinoma, perineal region, abdominoperineal resection.

\section{Resumen}

Introducción: El tumor de Buschke-Löwenstein es una lesión cutánea benigna, secundaria a la infección por virus papiloma humano, usualmente se presenta como una gran masa exofítica genitoanal y tiene riesgo de evolucionar a carcinoma espinocelular. Dentro de su tratamiento existen varias alternativas, desde menos agresivas como quimio-radioterapia e inmunoterapia, que suelen tener alta tasa de recidiva, hasta la cirugía radical. Caso clínico: Presentamos el caso de un paciente masculino, con una lesión perianal de 15 años de evolución, inicialmente se sometió a terapias locales conservadoras y quimiorradioterapia y posteriormente recidivó con transformación maligna. Habiéndose confirmado histológicamente la presencia de carcinoma espinocelular, debió abordarse mediante una resección abdominoperineal rectal. Dicha cirugía determinó un gran defecto de cobertura perianal y perineal que fue reparado mediante colgajos músculo-cutáneos de gracilis y fasciocutáneos de muslo. Discusión: Si bien se han descrito algunos métodos de resección local, sólo la cirugía radical permite su eliminación completa disminuyendo el riesgo de recurrencia. Ello genera

*Recibido el 15 de septiembre de 2014 y aceptado para publicación el 17 de diciembre de 2014.

Los autores no refieren conflictos de interés.

Correspondencia: Dr. Ricardo Yáñez M. ricardoyanezm@gmail.com 
un defecto perianal de difícil manejo, para el cual existen varias opciones reconstructivas: injertos, colgajos locales y regionales, y, con menor frecuencia, colgajos libres. Se debe considerar que en aquellos defectos de gran tamaño, con gran pérdida de tejido, las opciones de reconstrucción del defecto con volumen y cobertura cutánea adecuada son limitadas. Presentamos nuestra experiencia con algunas de estas técnicas, entre las que destaca el colgajo de músculo gracilis, con los múltiples beneficios que posee.

Palabras clave: Neoplasia anal, tumor de Buschke-Löwenstein, colgajo gracilis.

\section{Introducción}

El condiloma acuminado gigante o tumor de Buschke-Löwenstein corresponde a una patología benigna, secundaria a la infección por virus papiloma humano, con una incidencia de $0,1 \%$ en población general y que puede tener transformación maligna ${ }^{1}$. Fue descrito por primera vez en el año 1896 por Buschke, y por Löwenstein en 1925 como un tumor del pene, sin embargo, puede presentarse en múltiples localizaciones como el área genital, región perineal y otras regiones como la vejiga ${ }^{2,3}$. Clínicamente se manifiesta como una gran masa exofítica de crecimiento rápido y agresivo en la región genital y/o perianal con aspecto arboriforme, que infiltra y destruye los tejidos sobre los que se asienta ${ }^{4}$. Histológicamente se trata de una lesión de aspecto benigno, sin atipias celulares, pero con potencial de invasión local, siendo su principal característica la capacidad de destrucción local, siendo considerado histológicamente entre el condiloma acuminado y el carcinoma escamoso invasor ${ }^{5,6}$. Para realizar el diagnóstico en general es orientador el examen físico, la tomografía axial computada (TC) de pelvis nos dará información acerca de la extensión en profundidad, siendo fundamental contar con la histología para confirmar el diagnóstico y para evaluar invasión perineural, diferenciación y profundidad tumoral, factores que son importantes para la etapificación y pronóstico de la enfermedad ${ }^{7}$.

Una vez sometido a resección local presenta una tasa de recurrencia que alcanza un $67 \%$ y un riesgo considerable de transformación neoplásica, que llega a un $20 \%$ en los condilomas acuminados, pero alcanza al 56\% en los tumores de Buschke-Löwenstein; la mortalidad reportada es de hasta $20-30 \% 8$.

La infección con virus papiloma humano (VPH) es el principal factor de riesgo ya que es responsable de una proliferación celular descontrolada por medio de la expresión de dos genes, E6 y E7, por un lado el gen E6 se une al p53, impidiendo la reparación del DNA y permitiendo la acumulación de errores genéticos; y por otro lado, el gen E7 se une a la proteína supresora de tumores $\mathrm{Rb}$, conduciendo a la proliferación celular9. Los VPH tipo 6 y 11 se detectan fundamentalmente en las lesiones condilomatosas benignas. Sin embargo, los VPH tipo 16 y
18 se encuentran habitualmente en lesiones con alto grado de displasia, carcinoma in situ y carcinoma invasivo, por lo que su presencia indicaría un mayor riesgo de transformación maligna. La inmunidad celular juega un papel fundamental en el control de la infección por el VPH. Por este motivo, el VPH afecta preferentemente a pacientes inmunocomprometidos, particularmente a pacientes con alteración de la inmunidad celular ${ }^{10}$.

Han sido descritas múltiples alternativas terapéuticas, desde las menos agresivas como quimioradioterapia e inmunoterapia hasta la cirugía radical. Se recomienda un enfrentamiento quirúrgico inicial para la eliminación completa del tumor y así evitar su recurrencia ${ }^{11}$. La extensión de la lesión y el compromiso de los planos profundos va a determinar finalmente la resección a realizar ${ }^{12}$. Dado que el defecto de cobertura frente a resecciones extensas será importante, se convierte la reconstrucción perineal en un gran desafío quirúrgico.

\section{Caso clínico}

Se presenta el caso de un hombre de 53 años de edad, heterosexual, con antecedentes de hemorroides internos grado II de larga data, sin antecedentes de enfermedades de transmisión sexual.

El año 2007 consultó por un aumento de volumen perianal lentamente progresivo, que se extendía hacia ambos glúteos con un diámetro máximo de 15 $\mathrm{cm}$ de 12 años de evolución (Figura 1a), asociado a sangrado escaso intermitente en los últimos seis meses. No relata historia de baja de peso, ni otros síntomas sugerentes de compromiso sistémico. Dentro de los exámenes serológicos se solicita VDRL que resulta no reactivo y ELISA para VIH que es negativo. Se realizó una biopsia incisional a la lesión que fue compatible con condiloma acuminado gigante, sin signos histopatológicos de malignidad.

Se decidió realizar tratamiento ambulatorio mediante electrofulguración por parcialidades en dos sesiones, persistiendo una lesión residual, que fue resecada ampliamente un año después. En dicho procedimiento se evidenció infiltración de los espacios isquiorrectales en el plano profundo. La biopsia diferida fue compatible con carcinoma espinocelular 
bien diferenciado, papilomatoso, sin permeaciones vasculares, con infiltración hasta el tejido adiposo isquiorrectal y que comprometía los bordes quirúrgicos. Se discutió el caso en el comité oncológico multidisciplinario, donde se evaluó la necesidad de realizar una resección abdominoperineal rectal (Cirugía de Miles) versus quimio-radioterapia de acuerdo al protocolo de N. Nigro (Quimioterapia con Mitomicina-C y 5-Fluoruracilo asociado a radioterapia). El paciente tomó una decisión informada hacia esta última alternativa buscando evitar una colostomía definitiva. También con este tratamiento la respuesta clínica de la lesión fue parcial, quedando en control clínico periódico.

Posteriormente se evidenció un rápido crecimiento de las lesiones perianales residuales, y sangrado recurrente. Al séptimo mes de seguimiento se le realizó una TC de cerebro, tórax, abdomen y pelvis, donde se descartó compromiso sistémico y se observó infiltración tumoral en recto, grasa isquiorrectal y músculos elevadores del ano, sin infiltración ósea ni vesical (Figura 1b). Se repitieron los exámenes VDRL y ELISA-VIH, que resultaron negativos. Nuevamente se le planteó la situación al paciente, y esta vez accedió al tratamiento quirúrgico propuesto.

En enero de 2010 se realizó una resección abdominoperineal de recto, que comprendió hasta los músculos elevadores del ano (Figuras 2 y 3). Para dejar aislada cavidad peritoneal se realizó un cierre del saco peritoneal en la pelvis y cobertura con un colgajo pediculado de epiplón mayor basado en la arteria gastroepiploica izquierda. Secundario a la amplia resección realizada quedó un defecto de cobertura considerable en el periné, de aproximada- mente $15 \mathrm{~cm}$ de diámetro y que en profundidad se extendía hasta el espacio presacro.

Para lograr reconstruir esta región, proporcionando volumen en el espacio residual pelviano y a la vez dando cobertura cutánea, se realizaron distintos colgajos musculares, musculocutáneos y fasciocutáneos. Con el paciente en posición de litotomía, en el muslo derecho se diseñó un colgajo fasciocutáneo medial y en el muslo izquierdo un colgajo miocutáneo de gracilis. Con la finalidad de proporcionar volumen se realizó un colgajo pediculado de músculo gracilis del muslo derecho, que logró cubrir parcialmente el defecto pelviano; del mismo muslo se levantó un colgajo fasciocutáneo medial para lograr cobertura cutánea. En el muslo izquierdo se realizó un colgajo músculo-cutáneo de gracilis, que proporcionó volumen y una paleta cutánea. Se realizó el inset de los colgajos muscular de gracilis derecho y miocutáneo de gracilis izquierdo y se logró cubrir el defecto pelviano, con un volumen adecuado. Con el colgajo fasciocutáneo derecho asociado a la paleta cutánea de gracilis izquierdo se logró dar cobertura cutánea como se muestra en las Figuras 4 y 5.

El paciente evolucionó en malas condiciones generales en el postoperatorio precoz. Al tercer día se evidenció salida de material fecaloídeo por el drenaje de la cavidad abdominal y presentó un shock séptico severo asociado a falla orgánica múltiple, requiriendo el uso de drogas vasoactivas en la Unidad de Tratamiento Intensivo. Se realizó una exploración y se evidenció necrosis y dehiscencia del extremo distal de la colostomía terminal con peritonitis estercorácea en los cuatro cuadrantes, por lo que se realizó aseo quirúrgico y reconstrucción

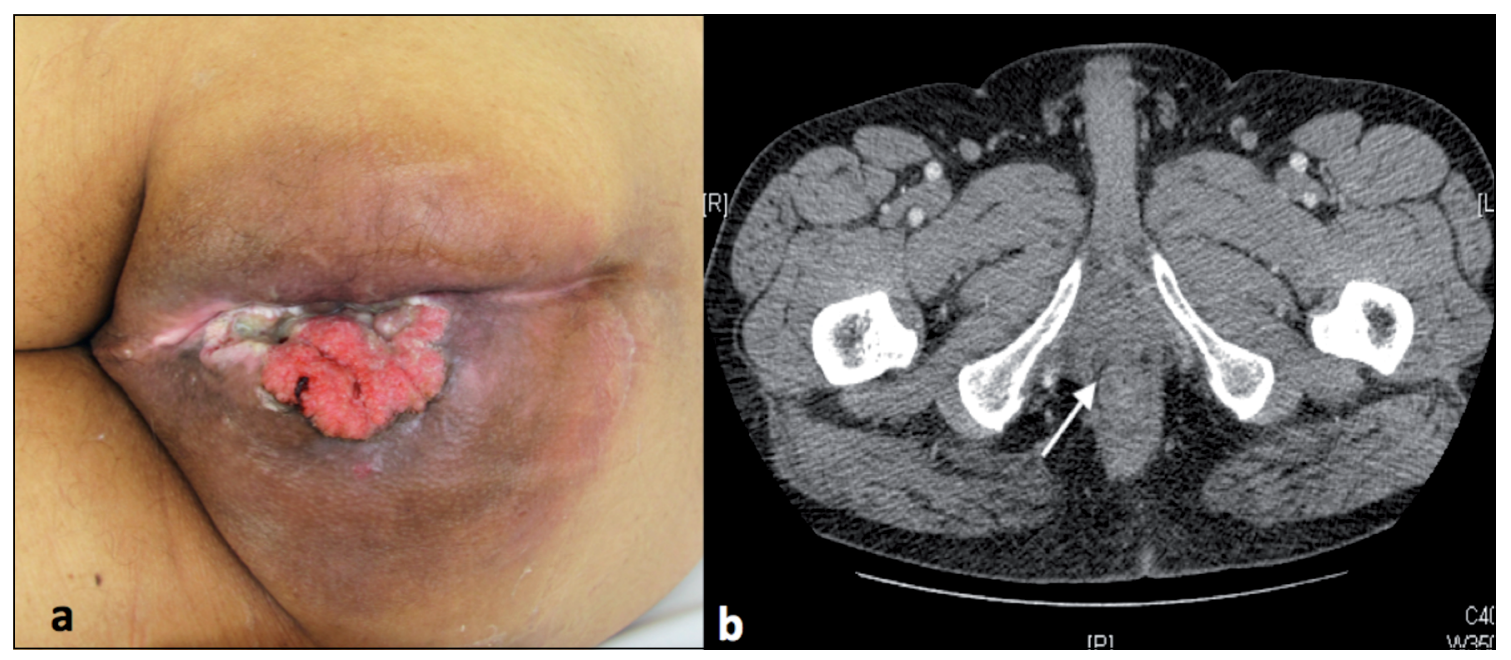

Figura 1. a) Lesión perianal que se extendía hacia ambos glúteos con un diámetro máximo de $15 \mathrm{~cm}$, de 12 años de evolución; b) Tomografía axial computarizada de pelvis donde se observa infiltración tumoral rectal. 


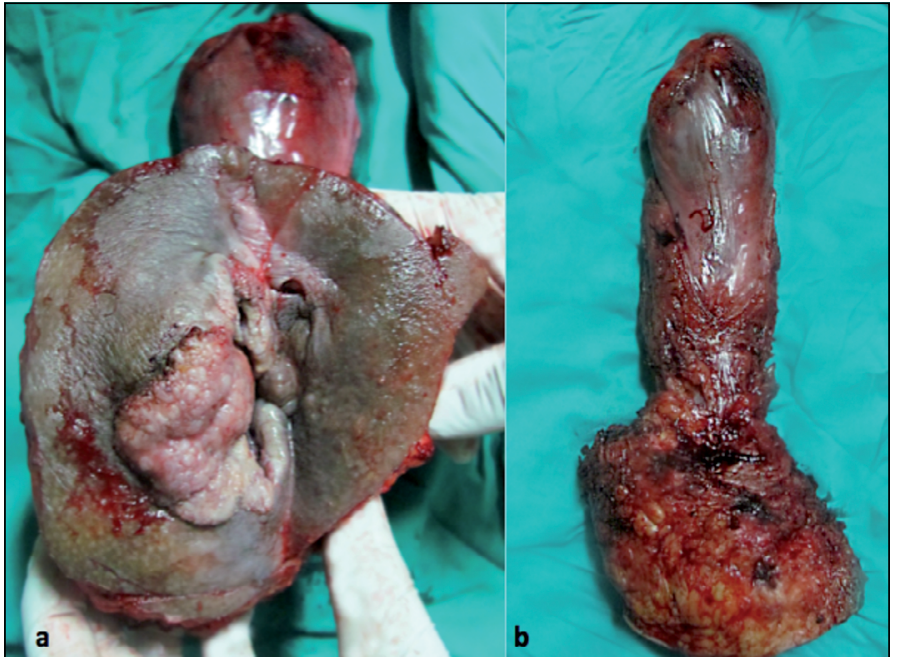

Figura 2. Pieza operatoria, luego de amplia resección perianal: a) Cara inferior; b) Cara anterior.

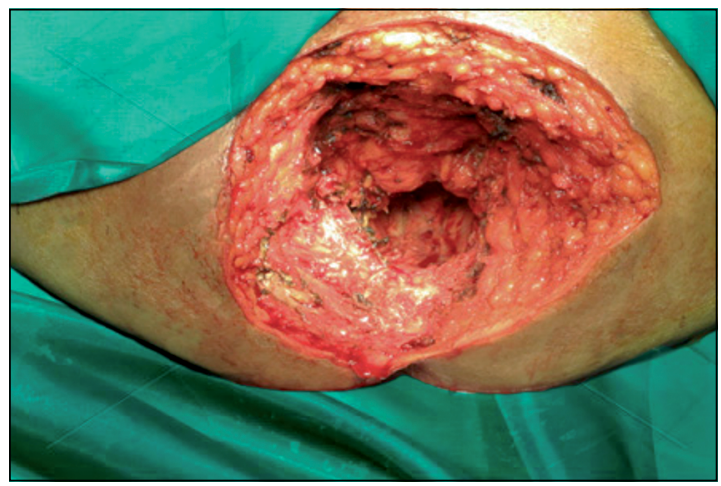

Figura 3. Defecto de cobertura luego de resección. de la colostomía. En la pelvis se prefirió un manejo conservador instalando un sistema de irrigaciónaspiración que se mantuvo por cinco días, hasta que los débitos fueron escasos (<30 cc/día) y serosos. Desde el punto de vista perineal se mantuvo con curaciones periódicas, con los colgajos vitales y sin presentar dehiscencia del cierre perineal.

El paciente mejoró progresivamente y tras una hospitalización de alrededor de dos meses fue dado de alta en buenas condiciones. En el control alejado a 1 año de la cirugía el paciente presenta buen resultado estético y funcional, sin evidencias clínicas de recidiva (Figura 6).

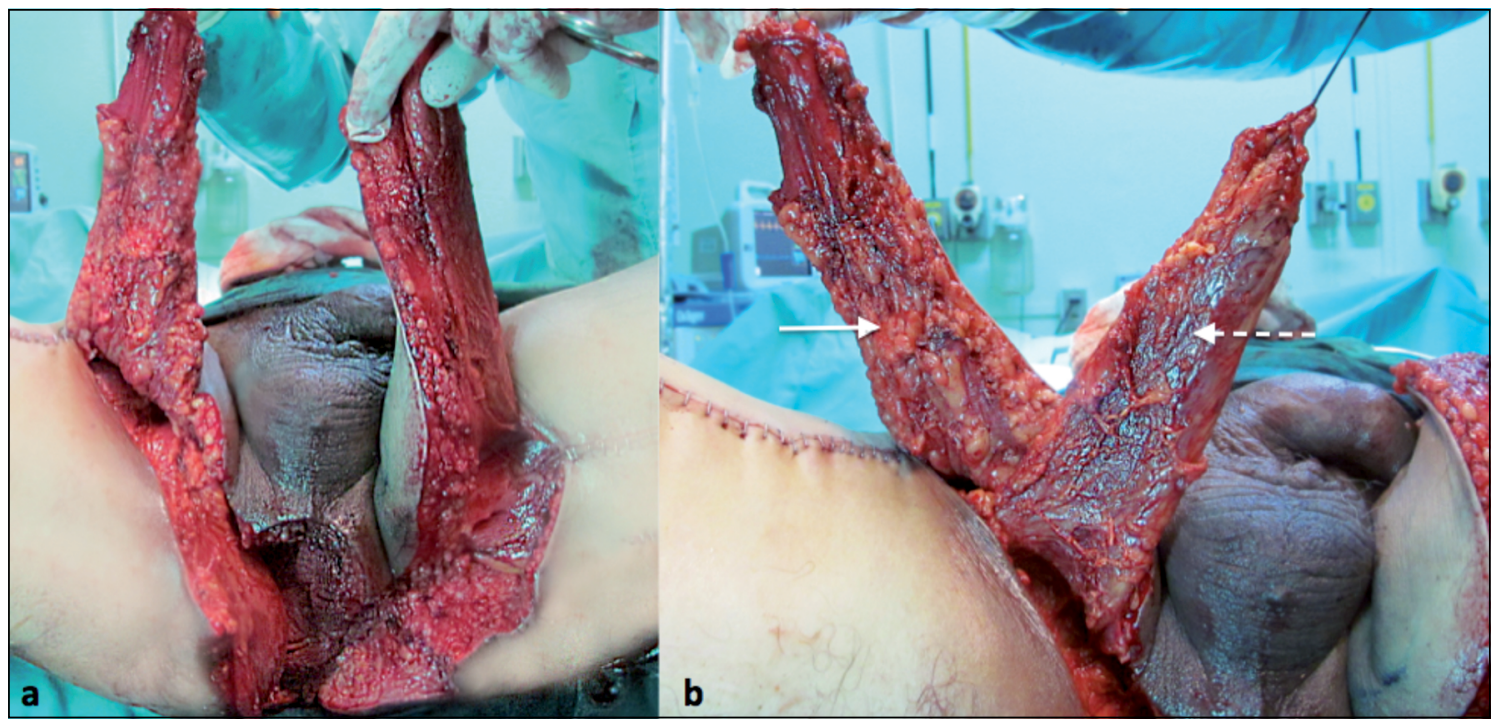

Figura 4. a) Colgajo fasciocutáneo medial de muslo derecho y colgajo musculocutáneo gracilis izquierdo; b) Colgajo fasciocutáneo medial de muslo derecho (línea continua) y colgajo músculo gracilis derecho (línea discontínua). 


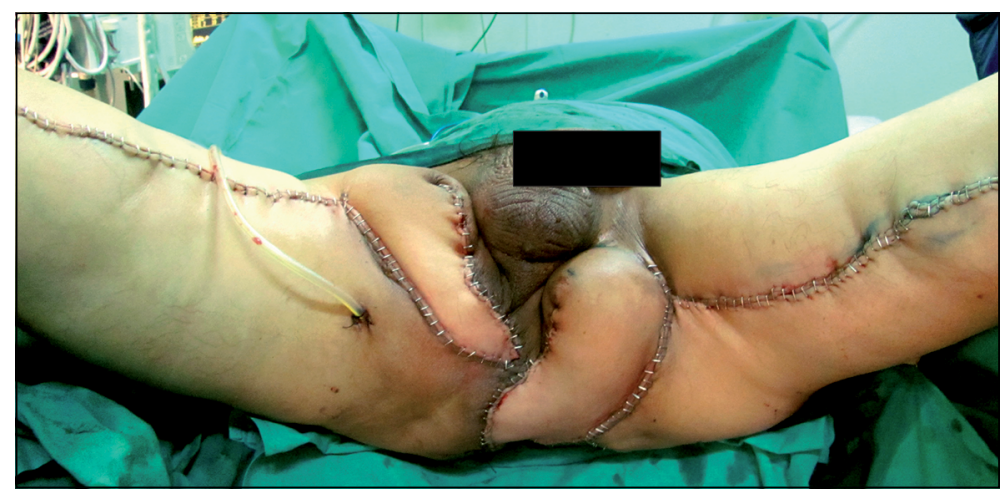

Figura 5. Intraoperatorio, luego de cierre defecto perianal.

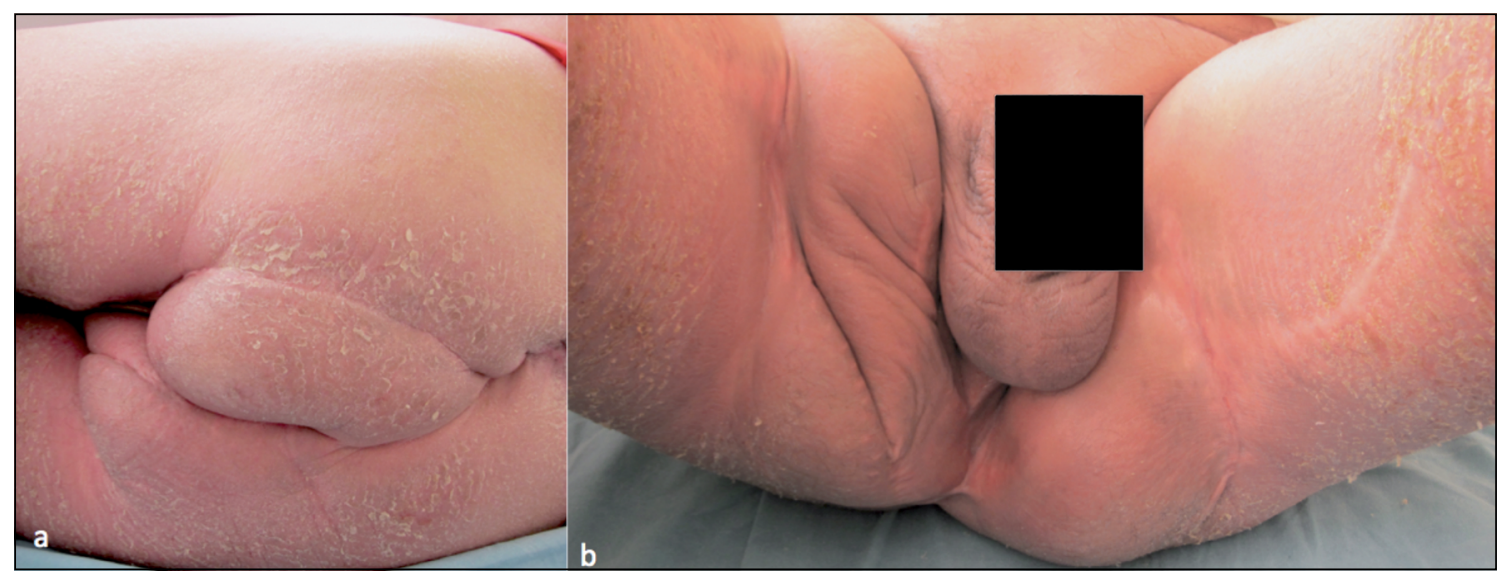

Figura 6. Control alejado a 1 año de la cirugía, sin evidencias clínicas de recidiva. Visión posterolateral (a) y anterior (b).

\section{Discusión}

Los condilomas acuminados extensos que presentan características de invasión destructiva local han sido llamados tumores de Buschke-Lowenstein, condilomas gigantes y carcinomas verrucosos. Se originan desde lesiones por VPH y pueden afectar cualquier porción de la región anogenital. Los condilomas gigantes son generalmente de crecimiento lento y la historia clínica muchas veces revela que la lesión ha estado presente por varios años antes de la presentación. Por otra parte, son localmente agresivos y destructivos respecto del tejido adyacente, sin embargo, rara vez presentan metástasis a distancia. Un subgrupo de pacientes tiene defectos inmunes identificables, más comúnmente VIH, y en estos pacientes la terapia antirretroviral altamente activa (HAART) ha demostrado disminuir la agresividad del tumor. Aún no está claro si se trata de un continuo de la neoplasia intraepitelial anal o una desviación ${ }^{13}$.
La resección local amplia actualmente es el pilar del tratamiento. Dado que el tumor puede comprometer por completo la circunferencia de la piel perianal y extenderse una distancia variable sobre la piel del glúteo no es poco común la escisión por parcialidades y en etapas ${ }^{14}$. Al igual que otras neoplasias, existen distintas alternativas para lograr la cobertura del defecto. En el caso presentado y debido a la progresión de la lesión a carcinoma escamoso la resección debió ser amplia para lograr márgenes negativos y evitar la recurrencia, como se observa en las Figuras 3 y 4, la reconstrucción fue una gran tarea.

El objetivo de la cirugía reconstructiva en pacientes con cáncer que han sido sometidos a cirugía resectiva es restaurar forma y función. Dicho objetivo se logra de mejor manera reemplazando el tejido resecado (tejido adiposo, óseo, nervio, piel, etc.) por tejido similar. Las opciones reconstructivas van desde las medidas conservadoras tales como cierre primario y el uso de colgajos locales e injertos de 
piel hasta métodos reconstructivos más complejos, tales como el uso de colgajos pediculados o colgajos libres microquirúgicos ${ }^{15}$. Asimismo es importante que el momento en que se realiza la reconstrucción por una resección oncológica no interfiera con el objetivo último de obtener márgenes quirúrgicos negativos. Por otra parte, si la remoción completa de una lesión resulta en un gran defecto que debe ser reparado inmediatamente, es fundamental la planificación preoperatoria en conjunto del cirujano reconstructivo con el cirujano oncólogo para determinar la estrategia conociendo aproximadamente la lesión resultante y las alternativas de sitios dadores que se podrán utilizar con seguridad para reconstruir el defecto. En la misma línea es importante considerar el pronóstico del paciente al evaluar las alternativas terapéuticas, aun considerando esto la reconstrucción, en el contexto de mejorar la calidad de vida del paciente, es muchas veces considerada incluso en un escenario paliativo. El timing de la reconstrucción muchas veces es determinado por el estado del tumor y los márgenes quirúrgicos. La reconstrucción inmediata se refiere a realizar la reconstrucción final en un solo tiempo con la cirugía inicial, una vez que el tumor es resecado. La reconstrucción diferida describe la práctica de retrasar la reconstrucción final, ya sea por razones médicas o por preferencias del paciente. Ciertos factores tales como edad avanzada, múltiples comorbilidades o la necesidad de control locorregional con radioterapia adyuvante también deben ser considerados en el timing y pueden ser mandatorios para una reconstrucción inmediata, incluso sin conocimiento del estado de los márgenes quirúrgicos ${ }^{16}$.

La cobertura inmediata con tejido bien vascularizado es el objetivo primario de la reconstrucción posterior a la escisión neoplásica, así los planos son mejor diferenciados y el lecho tiene menor o nula fibrosis. Al realizarla diferidamente existe tejido cicatrizal, fibrosis y contractura del tejido en el defecto, lo que puede impedir resultados óptimos desde el punto de vista funcional y estético ${ }^{17,18}$.

La reconstrucción perineal representa un desafío quirúrgico único, ya que la función y forma del periné es distinta de la de otras regiones del cuerpo. El periné es importante para el embarazo, actividad sexual, movilidad de la cadera y motilidad intestinal y vesical. La piel y tejido graso del periné son muy sensibles a la presión y al tacto, son resistentes a la fricción, elásticos y resistentes al peso. Además la piel perineal es "acolchada", pigmentada y con vellos, lo cual la convierte en una región difícil de asemejar con tejido a distancia ${ }^{19}$.

En un periné irradiado, como nuestro caso, puede ser utilizado un colgajo local o regional. Pequeños defectos de piel en el periné pueden ser reparados con un colgajo de rotación, tal como un colgajo romboidal. Los colgajos rotacionales son más efectivos cuando son utilizados en las caras laterales y posteriores, los cuales tienen mayor laxitud. Grandes defectos pueden requerir colgajos fasciocutáneos sensibilizados, como el colgajo fasciocutáneo posterior de muslo, o musculares como el colgajo pediculado de gracilis. Defectos mayores del periné también pueden ser reconstruidos con un colgajo pediculado miocutáneo anterolateral del muslo, en el cual pueden incluirse una cantidad variable de piel, tejido adiposo, y pueden ser elevados y transferidos fascia y músculo vasto lateral para poder restaurar volumen y contorno al defecto ${ }^{20}$.

En casos de gran defecto de cobertura cutánea asociado a una pérdida importante de volumen, como es nuestro caso, las alternativas más utilizadas y recomendadas son por una parte el colgajo miocutáneo vertical de recto abdominal (VRAM) y el colgajo gracilis. La mayoría de los pacientes puede ser reconstruido utilizando el colgajo VRAM ya que el pedículo epigástrico inferior está intacto y en general se deja sólo un estoma en la pared abdominal. Este colgajo es adecuado para rellenar la pelvis y reemplazar grandes defectos cutáneos de periné. De esta manera el intestino delgado se mantiene fuera de la pelvis y se provee un tejido bien vascularizado que permitirá el cierre de la zona. Una modificación del colgajo VRAM es una paleta cutánea con orientación oblicua, basada en las perforantes periumbilicales, lo que permite un mayor largo del colgajo y mejor entrada en la pelvis y le otorga mejor cobertura sobre todo en pelvis masculinas, donde el largo y la profundidad son mayores que las femeninas. La zona dadora es cerrada primariamente, generalmente $\sin$ necesidad de reemplazo fascial con material protésico ${ }^{21}$.

El colgajo gracilis tiene amplias aplicaciones en cirugía reconstructiva, puede ser utilizado como cobertura vascularizada en distintas lesiones complejas, tanto como colgajo de rotación regional o como colgajo libre microvascularizado. Como colgajo pediculado, la versatilidad del colgajo muscular o musculocutáneo de gracilis lo transforma en una excelente opción para reconstrucción perineal así como para cobertura isquiática ${ }^{22}$. Es particularmente útil para cobertura de defectos medianos en regiones pobremente vascularizadas, tales como la extremidad inferior o en zonas irradiadas. Por otra parte, anatómicamente es ideal, ya que posee un pedículo vascular constante y de un calibre adecuado y a la vez no es crítico para la irrigación de la extremidad inferior. Asimismo, posee un nervio motor único que no inerva a otros músculos. El músculo puede utilizarse en su longitud total para cubrir grandes áreas o puede ser recortado cuando 
es necesaria una cantidad mínima de músculo iner$\operatorname{vado}^{23}$. La localización de su pedículo es favorable para la rotación cuando es utilizado para resolver algunos de los mayores problemas en la región perineal e inguinal, tales como fístulas, injertos vasculares expuestos y lesiones que produzcan incontinencia anal ${ }^{24}$.

Otro uso muy relevante se le ha dado como músculo funcional, donde no sólo es revascularizado, sino también reinervado con función motora, como es el caso de su aplicación en la reanimación facial ${ }^{25}$. Todo lo anterior lo convierte en técnica de elección en la cirugía reparadora, siendo uno de los colgajos reconstructivos básicos que es indispensable conocer y utilizar pues que nos permitirá obtener resultados exitosos por su gran versatilidad y por su baja morbilidad $^{26}$.

\section{Referencias}

1. Paraskevas KI, Kyriakos E, Poulios EE, Stathopoulos V, Tzovaras AA, Briana DD. Surgical management of giant condyloma acuminatum (Buschke-Löewenstein tumor) of the perianal region. Dermatologic Surgery 2007;33:638-44.

2. Buschke A, Lowenstein L. Über Karcinomahnliche Condylomata acuminata des Penis. Klin Wochenschr 1925;4:1726-8.

3. Wiedemann A, Diekmann W, Holtmann G, Kracht H. Report of a case with gigant condyloma (BuschkeLowenstein Tumor) localized in the bladder. J Urol. 1995;153:1222-4.

4. Hernández BY, Barnholtz-Sloan J, German RR, Giuliano A, Goodman MT, King JB, et al. Burden of invasive squamous cell carcinoma of the penis in the United States, 1998-2003. Cancer 2008;113:2883-91.

5. Yanofsky VR, Mercer SE, Phelps RG. Histopathological variants of cutaneous squamous cell carcinoma: a review. J Skin Cancer 2011;2011:210813. doi: 10.1155/2011/210813. Epub 2010 Dec 29.

6. Petter G, Haustein UF. Histologic subtyping and malignancy assessment of cutaneous squamous cell carcinoma. Dermatol Surg. 2000;26:521-30.

7. Buethe D, Warner C, Miedler J, Cockerell CJ. Focus Issue on Squamous Cell Carcinoma: Practical Concerns Regarding the 7th Edition AJCC Staging Guidelines. J Skin Cancer 2011;2011:156391. doi: 10.1155/2011/156391. Epub 2010 Nov 22.

8. Chu QD, Vezeridis MP, Libbey NP, Wanebo HJ. Giant condyloma acuminatum (Buschke-Lowenstein Tumor) of the anorectal and perianal regions: analysis of 42 cases. Dis Colon Rectum 1994;37:950-7.

9. Oh JE, Kim JO, Shin JY, Zhang XH, Won HS, Chun $\mathrm{SH}$, et al. Molecular genetic characterization of p53 mutated oropharyngeal squamous cell carcinoma cells transformed with human papillomavirus E6 and E7 oncogenes. Int J Oncol. 2013;43:383-93.

10. Machalek DA, Poynten M, Jin F, Fairley CK, Farnsworth A, Garland SM, et al. Anal human papillomavirus infection and associated neoplastic lesions in men who have sex with men: a systematic review and metaanalysis. Lancet Oncol. 2012;13:487-500.

11. Trombetta LJ, Place RJ. Giant condyloma acuminatum of the anorectum: Trends in epidemiology and management. Dis Colon Rectum 2001;44:1878-86.

12. Dolanc R, Kocher T, Langer I, Marti WR, Pierer G, Harder F. Malignant transformation of perianal Buschke-Löwenstein tumor. Extensive abdominoperineal rectum excision and reconstruction with transpelvic myocutaneous rectus abdominis muscle flap. Chirurg. 2002;73:370-4.

13. De Toma G, Cavallaro G, Bitonti A, Polistena A, Onesti MG, Scuderi N. Surgical management of perianal giant condyloma acuminatum (Buschke-Löwenstein tumor). Report of three cases. Eur Surg Res. 2006;38:418-22.

14. Cintron JR. Buschke-Lowenstein tumor of the perianal and anorectal region. Semin Colon Rectal Surg. 1995;6:135-9.

15. Neligan PC. Principles. En: Neligan PC. Plastic Surgery, Third Edition. Washington, USA: Editorial: Elsevier Saunders 2012;647-98.

16. Khoo AK, Skibber JM, Nabawi AS, Gurlek A, Youssef AA, Wang B, et al. Indications for immediate tissue transfer for soft tissue reconstruction in visceral pelvic surgery. Surgery 2001;130:463-9.

17. Reece GP, Schusterman MA, Pollock RE, Kroll SS, Miller MJ, Baldwin BJ, et al. Immediate versus delayed free-tissue transfer salvage of the lower extremity in soft tissue sarcoma patients. Ann Surg Oncol. 1994;1:11-7.

18. Shibata D, Hyland W, Busse P, Kim HK, Sentovich SM, Steele G Jr, Bleday R. Immediate reconstruction of the perineal wound with gracilis muscle flaps following abdominoperineal resection and intraoperative radiation therapy for recurrent carcinoma of the rectum. Ann Surg Oncol. 1999;6:33-7.

19. Ducic I, Dayan JH, Attinger CE, Curry P. Complex perineal and groin wound reconstruction using the extended dissection technique of the gracilis flap. Plast Reconstr Surg. 2008;122:472-8.

20. Wei FC, Jain V, Celik N, Chen HC, Chuang DC, Lin $\mathrm{CH}$. Have we found an ideal soft-tissue flap? An experience with 672 anterolateral thigh flaps. Plast Reconstr Surg. 2002;109:2219-26.

21. Ali RS, Bluebond-Langner R, Rodríguez ED, Cheng $\mathrm{MH}$. The versatility of the anterolateral thigh flap. Plast Reconstr Surg. 2009;124(6 Suppl):e395-407.

22. Fattah A, Figus A, Mathur B, Ramakrishnan VV. The transverse myocutaneous gracilis flap: technical refinements. J Plast Reconstr Aesthet Surg. 2010;63:305-13.

23. Lykoudis EG, Spyropoulou GA, Vlastou CC. The conjoint medial circumflex femoral perforator and gracilis 
R. YÁÑEZ M. y cols.

muscle free flap: anatomical study and clinical use for complex facial paralysis reconstruction. Plast Reconstr Surg. 2005;116:1589-95.

24. Morasch MD, Sam AD 2nd, Kibbe MR, Hijjawi J, Dumanian GA. Early results with use of gracilis muscle flap coverage of infected groin wounds after vascular surgery. J Vasc Surg. 2004;39:1277-83.

25. Rozen S, Harrison B. Involuntary movement during mastication in patients with long-term facial paralysis reanimated with a partial gracilis free neuromuscular flap innervated by the masseteric nerve. Plast Reconstr Surg. 2013;132:110e-116e.

26. Zenn MR, Jones G. Thigh: Gracilis and TUG/TMG Flaps. En: Reconstructive Surgery: Anatomy, Technique \& Clinical Applications. Missouri, USA: Editorial QMP, 2012;1419-65. 